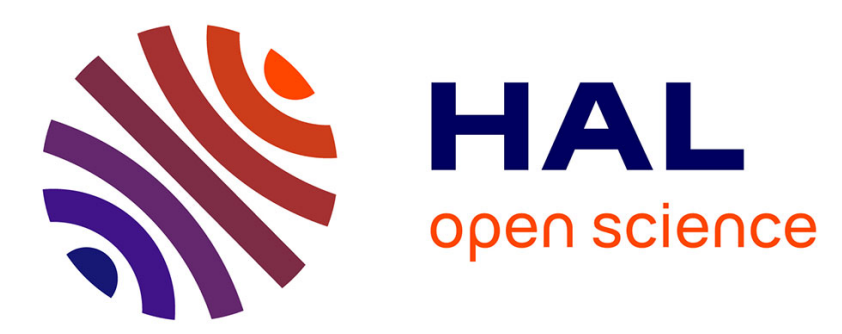

\title{
Thermal characterization of bulk and thin film materials using the mirage-method
}

\author{
W. Hurler, M. Pietralla
}

\section{To cite this version:}

W. Hurler, M. Pietralla. Thermal characterization of bulk and thin film materials using the mirage-method. Journal de Physique IV Proceedings, 1994, 04 (C7), pp.C7-627-C7-630. 10.1051/jp4:19947148. jpa-00253206

\section{HAL Id: jpa-00253206 https://hal.science/jpa-00253206}

Submitted on 1 Jan 1994

HAL is a multi-disciplinary open access archive for the deposit and dissemination of scientific research documents, whether they are published or not. The documents may come from teaching and research institutions in France or abroad, or from public or private research centers.
L'archive ouverte pluridisciplinaire HAL, est destinée au dépôt et à la diffusion de documents scientifiques de niveau recherche, publiés ou non, émanant des établissements d'enseignement et de recherche français ou étrangers, des laboratoires publics ou privés. 


\title{
Thermal characterization of bulk and thin film materials using the mirage-method
}

\author{
W. Hurler and M. Pietralla \\ Abteilung.für Experimentelle Physik, Universität Ulm, 89069 Ulm, Germany
}

\begin{abstract}
The photothermal laser beam deflection (PTD) is used to measure the thermal properties of bulk solids and thin film materials. A complete theoretical treatment of the miragedeflection in the case of a 4 layer-model (gas/film/substrate/backing) and a line heating source has been performed. The thermal properties can be obtained by fitting the theoretical expression to the experimental data. The experimental setup is described and experimental results for the thermal diffusivities of bulk solids over a range of 3 decades are presented. The errors caused by an incorrect assignment of fixed parameters in the non-linear least-square-fitting procedure are studied. A sensitivity study for a film-substrate-system is shown.
\end{abstract}

\section{INTRODUCTION}

The photothermal beam deflection method offers the possibility to measure the thermal diffusivity contactless and without any need of sample preparation.

In a typical mirage setup [1][2] the thermal wave is generated locally in the sample by a modulated focused Gaussian laser beam. Using this heating mode difficulties can occur for various materials:

a. To obtain a good signal-to-noise ratio the sample must absorb a minimum amount of energy.

If the deposited energy density is too high, this can result in a damage of the material (e.g. very thin polymer foils) or can produce a modification of the sample properties (e.g. structure modification at diamond-like-carbon films [3]).

b. Polycrystalline materials often show strong local changes of the thermal properties and many pointlike defects. This may be due to the heterogeneous structure of the sample (e.g. CVD-diamond-films have micrometer sized crystallites). In many applications one is only interested in the over the whole sample averaged thermal property.

To overcome this troubles we use a line heating source instead of a point-like excitation (Fig. [1]). For this heating mode we have developed a theory for the photothermal signal generation in a homogenous film-substrate-system, including the effect of finite optical absorption coefficients of film and substratelayer and the finite width of the probe and pump beam profile.

In order to find the thermal diffusivity and/or the thermal conductivity of the sample, one must measure the spatial and temporal thermal wave propagation respectively the temperature field $T(\vec{x}, t)$ of the sample. The temporal information is obtained by using several different modulation frequencies, the spatial information by scanning the temperature sensor (probe beam) over the sample surface. 


\section{EXPERIMENTAL EQUIPMENT}

The specimen is heated by an $\mathrm{Ar}^{+}$-Ion laser beam $(514 \mathrm{~nm})$ which was electro-optically modulated (Pockels-cell). With this configuration we get a real sinusoidally modulated laser beam in the frequency range from $1 \mathrm{~Hz}$ to $10 \mathrm{kHz}$. The line shape of the pump beam is produced by a cylindrical lens. A He-Nelaser $(632.8 \mathrm{~nm})$ is also focused by an achromatic lens to a $50 \mu \mathrm{m}\left(\mathrm{e}^{-2}\right)$-radius beam waist and skims above the sample surface.

The transversal deflection of the probe beam is detected by a four-quadrant-Si-photodiode. The outputs of the detector are preamplified and connected to a two-phase-lock-in amplifier. The heating beam is scanned across the probe beam using a motor-driven translation stage. In an experimental run on a sample 5 scans with different frequencies are made and all parameters are controlled automatically by a personal computer.

The in phase and quadrature components of the experimental data are transformed in the k-space and analysed by a multi-parameter least square fit [4].

For this evaluation an exact calibration of the absolute experimental phase in the used frequency regime is necessary. In the fitting procedure we use the known physical constants

- thickness of the substrate $I_{S}$ and the film $l_{f}$

- optical absorption coefficients $\mu_{\mathrm{s}}, \mu_{\mathrm{f}}$

- thermal conductivity $K_{S}$ and diffusivity $\alpha_{\mathrm{S}}$ of the substrate

as fixed parameters. The unknown parameters

- constant scaling factor

- thermal diffusivity $\alpha_{\mathrm{f}}$ and conductivity $\mathrm{K}_{\mathrm{f}}$ of the film

- radius of the probe beam $\mathrm{w}_{0}$

- intensity profile of the heating beam in $\mathrm{x}$-direction

- height of the probe beam above the sample $z_{0}$

are the fitting parameters.

\section{RESULTS}

With this method we are able to measure bulk and film-substrate systems. For thermal thick bulkmaterials with $\mathrm{K}_{\mathrm{S}} \gg \mathrm{K}_{\mathrm{g}}$ the influence of $\mathrm{K}_{\mathrm{S}}$ on the mirage-signal is almost as a constant scaling factor. In this case the only thermal information one can get is the diffusivity. Various bulk-materials were measured and the obtained thermal diffusivities are in good agreement with the literature values (Fig. [2]). The literature value of diamond is of undoped material. The fit results for a Bor-doped Si-wafer in the kand the $x$-space are shown in Fig. [3][4].

Measurements on thin film materials are in progress.

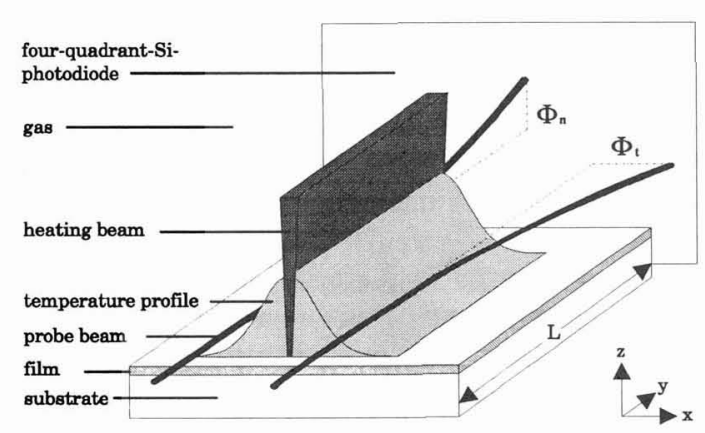

Fig. 1

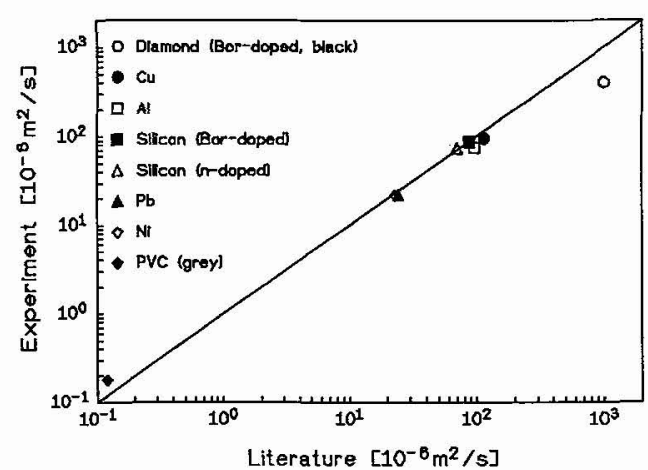

Fig. 2 


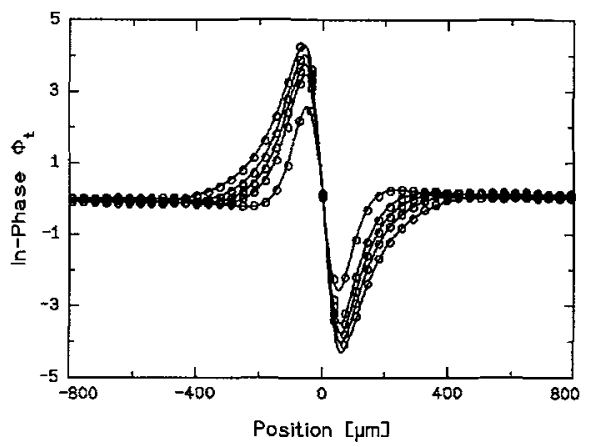

Fig. 3

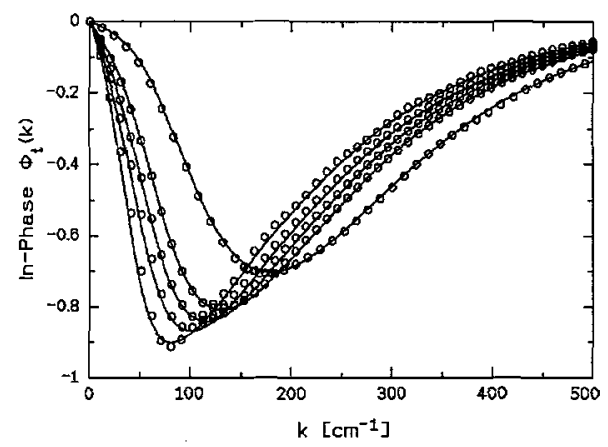

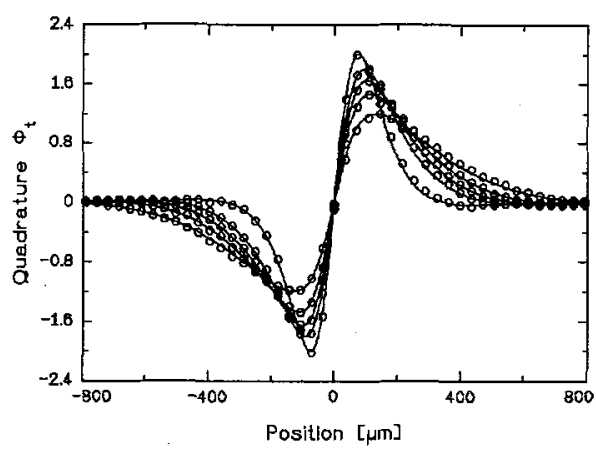

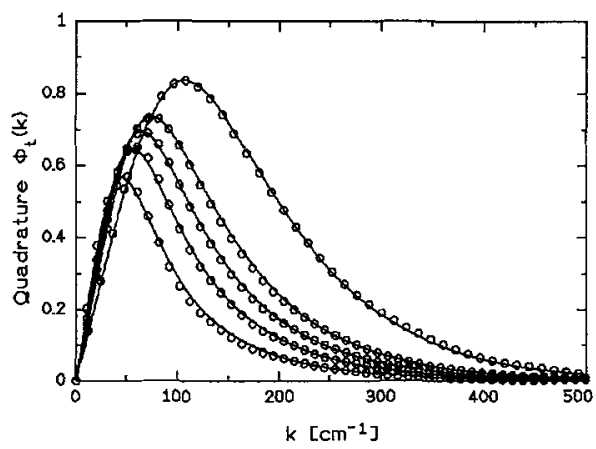

Fig. 4

\section{DISCUSSION}

The fixed parameters in the fitting procedure will be determined independently with a certain accuracy. We have studied the influence of the fit results $\alpha_{f}$ and $K_{f}$ when each of the fixed parameters is known with a definite error. For this calculation we simulated the mirage-signal of a Pb-film $\left(l_{f}=2 \mu \mathrm{m}, \mu_{\mathrm{f}}=10^{5}\right.$ $\left.\mathrm{cm}^{-1}\right)$ on a glass-substrate $\left(l_{\mathrm{S}}=1000 \mu \mathrm{m}, \mu_{\mathrm{S}}=0 \mathrm{~cm}^{-1}\right)$ at 5 different frequencies and doing the fit by varying the accuracy of one fixed parameter.

The resulting errors for the fit-determination of $\alpha_{\mathrm{f}}$ and $\mathrm{K}_{\mathrm{f}}$ are shown in Fig. [5]. In order to obtain a certain accuracy for the determined thermal properties of the film one must know the physical quantity $\alpha_{S}$ very exactly. The parameters $K_{S}$ and $l_{f}$ have a strong influence on the thermal conductivity $K_{f}, l_{S}$ and $\mu_{f}$ have not been determined absolute with that precision!

Determination of film-parameters using our method makes only sense, if the film-layer yields a measurable contribution to the whole mirage signal.

The smaller the difference between film and substrate effusivities and the thinner the film-layer, the less
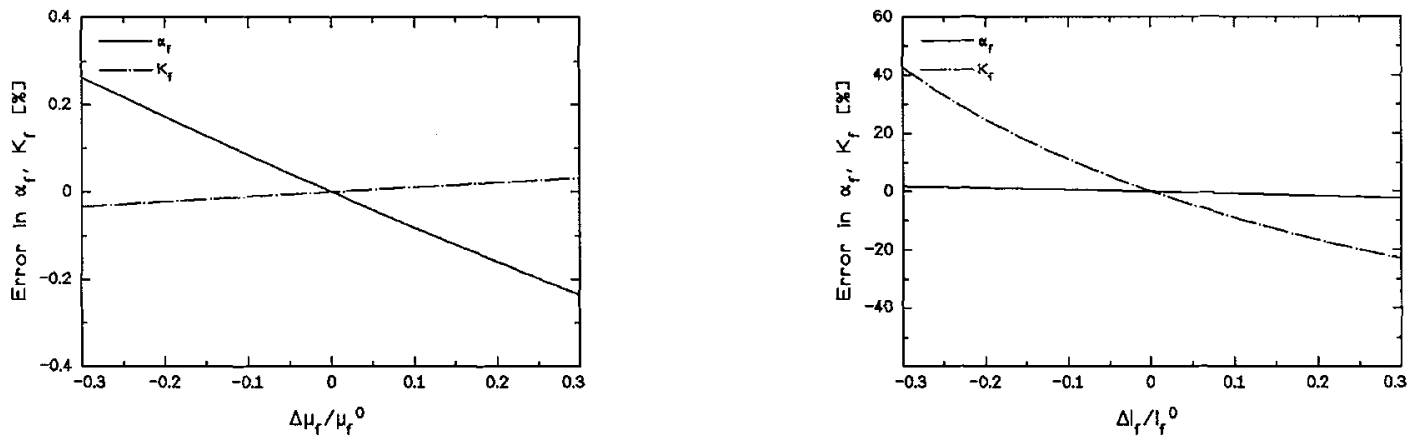

Fig. 5 

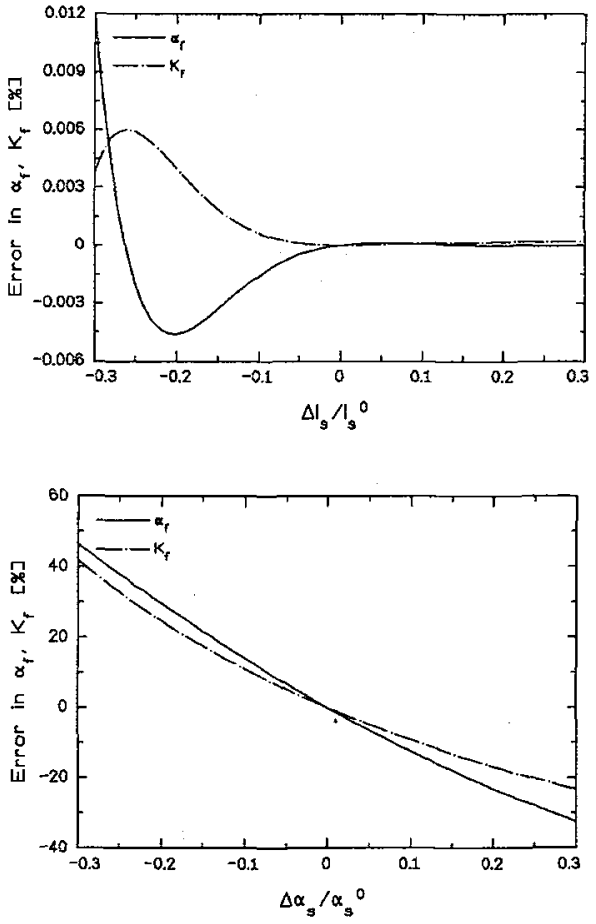

ad Fig. 5

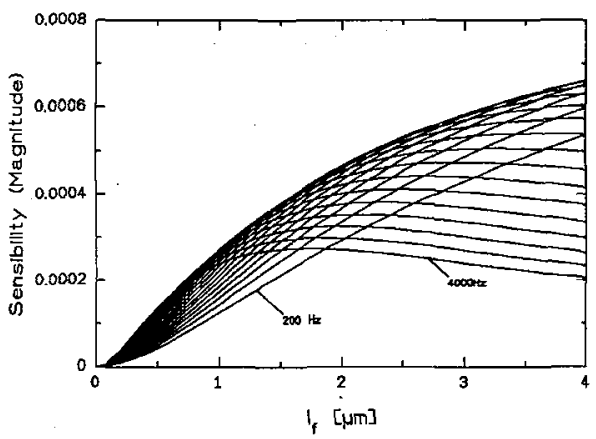

Fig. 6: Maxima of $S(k)$ as function of $\mathrm{I}_{f}$. Parameter: frequency $v=200 \mathrm{~Hz}-4000 \mathrm{~Hz}$ (step: $200 \mathrm{~Hz}$ )

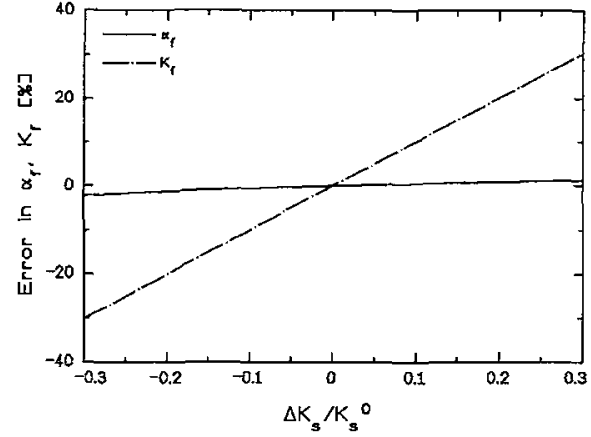

will be the possibility to extract film properties from the data. To estimate the best choice of frequencies and substrate parameters it is useful to calculate the sensitivity in the $\mathrm{k}$-space, defined as follows:

$$
\mathrm{S}_{\alpha_{\mathrm{f}}}=\alpha_{\mathrm{f}} \cdot \frac{\partial \Phi_{\mathrm{t}}(\mathrm{k})}{\partial \alpha_{\mathrm{f}}}
$$

with $\Phi_{\mathfrak{t}}(k)$ : Fouriertransform of the transversal deflection.

In Fig. [6] we have evaluated the sensitivity $S_{\alpha_{f}}$ of the magnitude and phase behaviour in the k-space versus $l_{f}$ and frequency $v$. We assumed an $\mathrm{Pb}$-film on a glasssubstrate.

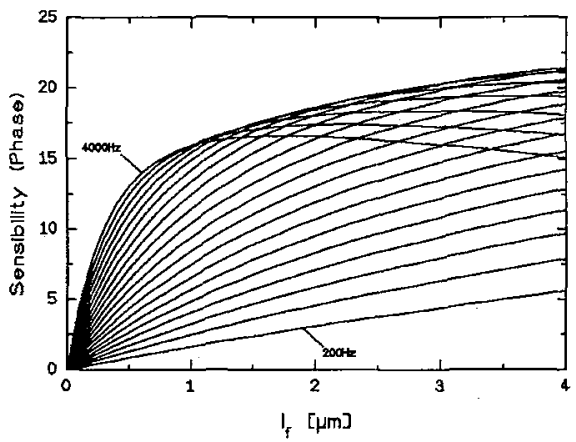

\section{REFERENCES:}

[1] L.C. Aamodt, J.C. Murphy, J. Appl. Phys 52 (8), p. 4903, (1981)

[2] P.K. Kuo, M.J. Lin, C. Reyes, L. Favro, R.L. Thomas, D. Kim, Can. J. Phys. 64, p. 1165, (1986)

[3] M. Bowden, D.J. Gardiner, J.M. Sonthall, J. Appl. Phys. 71 (1), p. 521, (1992)

[4] P.K Kuo, L. Wei, R.L. Thomas, R.W. Pryor, Photoacoustic and Photothermal Phenomena II (Springer Series in Optical Science, Vol. 62, ed.: J.C. Murphy, J.W. Maclachlan-Spicer, 1990), p. 124 